\title{
Efeitos do E27,5 Em Veículos, Motocicletas e Motor a Gasolina
}

\author{
Antonio Carlos Scardini Vilella ${ }^{1}$, Ricardo Almeida Barbosa de Sá ${ }^{1}$, Pedro Cafaro Vicentini ${ }^{1}$, \\ Rogério Nascimento de Carvalho ${ }^{1}$, Guilherme Bastos Machado ${ }^{1}$, Tadeu Cavalcante Cordeiro \\ de Melo ${ }^{1}$ e Katia Moniz da Silva ${ }^{1}$ \\ ${ }^{1}$ Petróleo Brasileiro S.A.
}

E-mails: antonio.villela@petrobras.com.br, rsa@ petrobras.com.br, pcvicentini@petrobras.com.br, rogerio.carvalho@petrobras.com.br, machadogb@ petrobras.com.br, tcm@ petrobras.com.br, kmsilva@ petrobras.com.br,

\section{RESUMO}

O artigo reporta o estudo feito pela PETROBRAS para avaliação técnica do impacto do aumento do teor de etanol anidro combustível na gasolina brasileira, de 25 para 27,5\% v/v, em motor, veículos e motocicletas movidos exclusivamente à gasolina.

No estudo foram realizados ensaios de emissões e autonomia em veículos e motocicletas em dinamômetro de chassis e ensaios de desempenho (partida e dirigibilidade a frio e retomada de velocidade) em pista, utilizando diferentes tecnologias de injeção de combustível, representativos das diferentes fases dos programas brasileiros de controle da poluição do ar (PROCONVE e PROMOT).

Observou-se ainda o efeito nas principais variáveis do motor, por meio das curvas características de desempenho em banco de provas, incluindo o impacto na temperatura dos gases de escape em motor com tecnologia de injeção direta. $\mathrm{O}$ mesmo foi feito em relação às propriedades físico-químicas contidas na especificação, com ênfase para os ensaios de volatilidade, lubricidade e estabilidade à oxidação (formação de goma).

Os resultados dos ensaios com gasolinas com teores de 25 e $27,5 \%$ de etanol anidro indicaram não haver alterações significativas, atendendo plenamente à especificação técnica da ANP e sem prejuízo para o funcionamento normal na frota circulante.

\section{INTRODUÇÃO}

Diante da possibilidade do governo federal determinar o aumento do teor máximo de etanol anidro de $25 \%$ para $27,5 \%$ na gasolina comercial brasileira, a PETROBRAS realizou uma avaliação de misturas gasolina-etanol com teores de 22, 25, 27,5 e 30\% v/v de EAC (Etanol Anidro Combustível) no tocante a emissões, autonomia e desempenho (partida e dirigibilidade a frio e retomada de velocidade) em veículos e motocicletas, desempenho em motor em banco de provas e ensaios analíticos de lubricidade e goma das misturas.

Foram escolhidos oito veículos a gasolina com diferentes tecnologias de alimentação de combustível, homologados de acordo com as fases L2 a L6 do Programa de Controle da Poluição do Ar por Veículos Automotores - PROCONVE. Adicionalmente, foram selecionadas cinco motocicletas a gasolina, com diferentes tecnologias que atendem às fases 
Pré-M1, M1, M2 e M3 do Programa de Controle da Poluição do Ar por Motociclos e Veículos Similares - PROMOT.

Os ensaios de desempenho em motocicletas não serão detalhados neste trabalho. Tais ensaios foram realizados pela Associação Brasileira dos Fabricantes de Motocicletas, Ciclomotores, Motonetas, Bicicletas e Similares - ABRACICLO, que considerou viável a utilização do $\mathrm{E} 27,5$.

Os resultados deste estudo foram informados ao Ministério de Minas e Energia, como subsídio para a aprovação técnica do aumento do teor máximo de etanol anidro na gasolina comercial para $27 \%$ [1].

\section{COMBUSTÍVEIS, VEÍCULOS E MOTOCICLETAS UTILIZADAS}

Os ensaios de emissões e autonomia de combustível foram realizados com gasolinas contendo $22,25,27,5$ e 30\% de etanol anidro. A gasolina base atende às especificações da gasolina padrão de emissões, conforme Resolução ANP $n^{\circ}$ 5/2005 [2] e o etanol anidro à Resolução ANP n ${ }^{\circ}$ 6/2005 [3]. Para os ensaios de desempenho em pista, curvas características em banco de provas e análises de volatilidade, lubricidade e estabilidade à oxidação, foram utilizadas gasolinas comerciais com 25, 27,5 e 30\% de etanol anidro.

Na seleção dos veículos e das motocicletas (tabelas I e II), buscou-se representatividade de fabricantes, quilometragem acumulada compatível com a idade do veículo, cilindradas e tecnologias de injeção de combustível em relação à frota circulante de veículos a gasolina. Segundo dados do último Inventário Nacional [4], em 2012, 36\% da frota de veículos de passeio era movida exclusivamente a gasolina, enquanto para a frota de motocicletas esse percentual era de $84 \%$. Considerando esta composição, os veículos selecionados para o trabalho representam cerca de $94 \%$ da frota de veículos a gasolina, enquanto as motos $100 \%$.

Tabela I - Principais características dos veículos

\begin{tabular}{c|c|c|c|c|c|c|c}
\hline $\begin{array}{c}\text { Código } \\
\text { Veículo }\end{array}$ & Fase & $\begin{array}{c}\text { Ano } \\
\text { /Modelo }\end{array}$ & $\begin{array}{c}\text { Km } \\
\text { rodada }\end{array}$ & $\begin{array}{c}\text { Cilindra } \\
\text { da }\end{array}$ & $\begin{array}{c}\text { Trans- } \\
\text { missão }\end{array}$ & $\begin{array}{c}\text { Catali- } \\
\text { sador }\end{array}$ & $\begin{array}{c}\text { Sistema de } \\
\text { Alimentação }\end{array}$ \\
\hline L2A & L2 & $1995 / 1996$ & 251030 & 1.0 & manual & Sim & $\begin{array}{c}\text { carburador } \\
\text { eletrônico }\end{array}$ \\
L2B & L2 & 1995 & $>141867$ & 1.6 & manual & Sim & injeção monoponto \\
L3A & L3 & 2001 & 155392 & 1.8 & automático & Sim & injeção multiponto \\
L3B & L3 & $1999 / 2000$ & 229332 & 1.0 & manual & Sim & injeção multiponto \\
L4A & L4 & 2008 & 98349 & 2.0 & automático & Sim & injeção multiponto \\
L5A & L5 & $2009 / 2010$ & 72471 & 1.6 & manual & Sim & injeção multiponto \\
L5B & L5 & 2010 & 40547 & 2.0 & automático & Sim & injeção multiponto \\
L6A & L6 & $2013 / 2014$ & 6035 & 1.6 & automático & Sim & turbo injeção direta \\
L6B & L6 & $2013 / 2014$ & 5333 & 1.6 & automático & Sim & turbo injeção direta
\end{tabular}


Tabela II - Principais características das motocicletas

\begin{tabular}{c|c|c|c|c|c|c}
\hline $\begin{array}{c}\text { Código } \\
\text { Moto }\end{array}$ & Fase do PROMOT & Ano & $\begin{array}{c}\text { Km } \\
\text { rodada }\end{array}$ & $\begin{array}{c}\text { Cilindra- } \\
\text { da }\end{array}$ & $\begin{array}{c}\text { Catali- } \\
\text { sador }\end{array}$ & $\begin{array}{c}\text { Sistema de } \\
\text { Alimentação }\end{array}$ \\
\hline PM1 A & PM1 & 2002 & 91719 & 125 & Não & carburador \\
M1 A & M1 & 2005 & 59374 & 150 & Não & carburador \\
M2 A & M2 & 2008 & 50307 & 125 & Não & carburador \\
M3 A & M3 & 2009 & 124 & 125 & Sim & injeção eletrônica \\
M3 B & M3 & 2010 & 105 & 300 & Sim & injeção eletrônica
\end{tabular}

Com relação ao estado de funcionamento, foram escolhidos veículos em boas condições de uso, entendendo como tal aqueles que não apresentassem problemas de dirigibilidade, nem superassem os limites de emissões dos programas de inspeção e manutenção veicular, estabelecidos na Resolução CONAMA 418/2009, independentemente de atenderem aos respectivos limites de homologação do PROCONVE. Sendo assim, não foi efetuada nenhuma manutenção especial nos veículos antes dos testes. Com isso pretendia-se que a amostra testada refletisse de forma mais realista a condição da frota nacional.

\section{ENSAIOS DE EMISSÕES E AUTONOMIA DE COMBUSTÍVEL}

\subsection{VEÍCULOS}

Os ensaios de emissões em dinamômetro de chassi foram realizados seguindo a norma NBR 6601 [5], com medição das emissões de hidrocarbonetos totais (THC), hidrocarbonetos não metano (NMHC), monóxido de carbono (CO), dióxido de carbono $\left(\mathrm{CO}_{2}\right)$ e óxidos de nitrogênio (NOx). A medição das emissões de aldeídos (formaldeído + acetaldeído) foi feita segundo a norma NBR 12026 [6] por meio de cromatografia liquida de alta eficiência (HPLC). A determinação da autonomia urbana e em estrada foi realizada pelo método do balanço de carbono, segundo a norma NBR 7024 [7].

Para permitir um grau de significância maior da análise estatística dos dados, foram realizados ao menos três ensaios em cada veículo com cada um dos combustíveis de teste.

Como primeiro passo, realizou-se o teste $\mathrm{F}$ da Análise de Variância (ANOVA), em separado para cada poluente e veículo, a fim de verificar em que casos o combustível tinha influência no resultado, considerando um nível de significância de $95 \%$ ( $\mathrm{p}=$ 0,05). Nos casos em que isso ocorreu, procedeu-se uma Análise de Regressão para um ajuste linear. O nível de significância para esta análise também foi $\mathrm{p} \leq 0,05\left(^{7}\right)$.

Uma vez estabelecido os modelos de regressão, estes foram usados para estimar as emissões de poluentes e a autonomia de combustível para os níveis testados, utilizando-se este valor para efetuar a comparação entre os resultados dos diferentes combustíveis. Nessas comparações, levou-se em conta o erro associado ao modelo de regressão levantado, de modo que quando a diferença entre os resultados era inferior ao seu intervalo de confiança, considerou-se não ser possível afirmar que existe diferença estatisticamente significativa ("s/dif."). 
Numa análise qualitativa de tendências, observou-se que, com o aumento do teor de etanol entre os níveis de 22 e 30\%v/v, houve manutenção ou redução nas emissões de hidrocarbonetos (THC e NMHC), $\mathrm{CO}$ e $\mathrm{CO}_{2}$. Para esse último gás, contudo, ocorreu uma exceção (tendência de aumento no veículo L2A) [8].

Com relação ao NOx, os veículos mais antigos (L2 e L3) também seguiram a tendência de manutenção ou redução. Nos veículos L4 em diante, verificou-se que houve tendência de aumento em um veículo (L5B), enquanto para os demais (L4A, L5A e L6A) não se pode afirmar que o combustível teve influência estatisticamente significativa no nível de emissão do poluente. Entretanto, vale ressaltar que no caso em que se verificou a elevação no NOx, o maior valor encontrado (veículo L5B com E30) foi $45 \%$ abaixo do respectivo limite do PROCONVE.

Para aldeídos observou-se uma tendência de aumento de emissões em alguns veículos. A maior emissão encontrada (L5A com E30) foi 95\% abaixo do limite do PROCONVE.

Em relação à autonomia (urbana e em estrada) percebeu-se uma tendência de redução em todos os veículos.

As tendências observadas confirmam as expectativas, pois a utilização de combustíveis com maior teor de etanol tende a empobrecer a mistura ar-combustível, o que em geral conduz a menores emissões de hidrocarbonetos e de $\mathrm{CO}$, porém, eventualmente também provoca um aumento no NOx e em aldeídos, além de uma redução na autonomia, neste caso devido ao menor conteúdo energético do etanol.

Esse comportamento é mais marcante em veículos com tecnologias antigas, representados neste trabalho pelos automóveis da Fase L2 do PROCONVE, que normalmente trabalham em regime de mistura rica (excesso de combustível). Já nos veículos mais recentes, o sistema de controle de emissões é concebido de forma a fazer com que se trabalhe a maior parte do tempo na região estequiométrica da mistura ar-combustível, o que faz com que pequenas variações no teor de oxigênio do combustível possam ser corrigidas pelo sistema, afetando pouco as emissões.

Entretanto, mesmo nesses veículos, durante a partida a frio costuma-se utilizar transitoriamente um regime de mistura rica, a fim de evitar falhas de funcionamento durante o aquecimento do motor. Como nessa situação o catalisador do veículo ainda não atingiu sua temperatura de máxima eficiência, a utilização de um combustível com maior teor de oxigênio pode levar momentaneamente às mesmas tendências comentadas acima.

A fim de verificar quais diferenças poderiam ser consideradas estatisticamente significativas em relação ao combustível com o qual os veículos foram homologados (E22) e a gasolina comercializada à época (E25), efetuou-se a comparação dos resultados obtidos a partir das retas de regressão, conforme descrito acima. Destaca-se que em muitos casos, mesmo tendo sido identificada uma tendência de variação com o teor de etanol, o erro associado à regressão não permitiu encontrar diferença estatisticamente significativa entre os combustíveis, nas faixas de interesse de comparação. 
As tabelas III a V apresentam a comparação entre os combustíveis E25, E27,5 e E30 contra a referência E22. Quando a utilização da técnica ANOVA indicou que a influência do combustível não era significativa, escreveu-se o código "s/dif.". Onde ela foi considerada significativa, calculou-se a emissão ou autonomia a partir das respectivas retas de regressão, além dos intervalos de confiança correspondentes. Quando houve superposição dos intervalos de confiança dos valores que estavam sendo comparados, novamente colocou-se "s/dif". Nos casos em que isso não ocorreu, procedeu-se o cálculo da diferença percentual entre os valores estimados, sendo que o sinal negativo antes do valor indica uma redução na emissão ou autonomia. Para melhor visualização, resultados que representam uma melhora no atributo estão destacados em verde, enquanto resultados piores estão em vermelho.

A tabela III indica uma tendência de redução no $\mathrm{CO}$ no escapamento dos veículos mais antigos (dois apresentaram redução de até $11 \%$ ), porém as demais diferenças não foram estatisticamente significativas. No que diz respeito à autonomia, somente em dois veículos pode-se detectar uma diminuição dos resultados no ciclo estrada (1\%).

Tabela III- Comparação entre emissões e autonomia com E25 e E22.

\begin{tabular}{c|l|l|l|l|l|l|l|l}
\hline \multicolumn{9}{c}{ E25 x E22 } \\
\hline Veículos & L2A & L2B & L3A & L3B & L4A & L5A & L5B & L6A \\
\hline $\begin{array}{c}\text { THC (L2, L3) \& } \\
\text { NMHC (L4, L5, L6) }\end{array}$ & s/dif. & s/dif. & s/dif. & s/dif. & s/dif. & s/dif. & s/dif. & s/dif. \\
\hline CO & $-11 \%$ & $-9 \%$ & s/dif. & s/dif. & s/dif. & s/dif. & s/dif. & s/dif. \\
\hline NOx & s/dif. & s/dif. & s/dif. & s/dif. & s/dif. & s/dif. & s/dif. & s/dif. \\
\hline Aldeídos & s/dif. & s/dif. & s/dif. & s/dif. & s/dif. & s/dif. & s/dif. & s/dif. \\
\hline $\mathrm{CO}_{2}$ & s/dif. & s/dif. & s/dif. & s/dif. & s/dif. & s/dif. & s/dif. & s/dif. \\
\hline Autonomia Urbana & s/dif. & s/dif. & s/dif. & s/dif. & s/dif. & s/dif. & s/dif. & s/dif. \\
\hline $\begin{array}{c}\text { Autonomia em } \\
\text { Estrada }\end{array}$ & s/dif. & s/dif. & s/dif. & $-1 \%$ & $-1 \%$ & s/dif. & s/dif. & s/dif. \\
\hline
\end{tabular}

Tabela IV- Comparação entre emissões e autonomia com E27,5 e E22.

\begin{tabular}{|c|c|c|c|c|c|c|c|c|}
\hline \multicolumn{9}{|c|}{$\mathrm{E} 27,5 \times \mathrm{E} 22$} \\
\hline Veículos & L2A & L2B & L3A & L3B & L4A & L5A & L5B & L6A \\
\hline $\begin{array}{c}\text { THC (L2, L3) \& } \\
\text { NMHC (L4, L5, L6) }\end{array}$ & s/dif. & s/dif. & s/dif. & s/dif. & s/dif. & s/dif. & s/dif. & s/dif. \\
\hline $\mathrm{CO}$ & $-21 \%$ & $-16 \%$ & s/dif. & s/dif. & $-10 \%$ & s/dif. & s/dif. & s/dif. \\
\hline NOx & s/dif. & s/dif. & s/dif. & s/dif. & s/dif. & s/dif. & s/dif. & s/dif. \\
\hline Aldeídos & s/dif. & s/dif. & $39 \%$ & s/dif. & s/dif. & s/dif. & s/dif. & s/dif. \\
\hline $\mathrm{CO}_{2}$ & s/dif. & s/dif. & s/dif. & s/dif. & $-1 \%$ & s/dif. & s/dif. & $-1 \%$ \\
\hline Autonomia Urbana & $-3 \%$ & s/dif. & s/dif. & s/dif. & $-1 \%$ & $-2 \%$ & s/dif. & s/dif. \\
\hline $\begin{array}{c}\text { Autonomia em } \\
\text { Estrada }\end{array}$ & $-1 \%$ & s/dif. & s/dif. & $-1 \%$ & $-2 \%$ & $-2 \%$ & $-2 \%$ & s/dif. \\
\hline
\end{tabular}


Tabela V- Comparação entre emissões e autonomia com E30 e E22.

\begin{tabular}{c|l|l|l|l|l|l|l|l}
\hline \multicolumn{7}{c}{ E30 x E22 } \\
\hline Veículo & L2A & L2B & L3A & L3B & L4A & L5A & L5B & L6A \\
\hline $\begin{array}{c}\text { THC (L2, L3) \& } \\
\text { NMHC (L4, L5, L6) }\end{array}$ & s/dif. & $-10 \%$ & s/dif. & s/dif. & s/dif. & $-27 \%$ & s/dif. & s/dif. \\
\hline CO & $-31 \%$ & $-23 \%$ & s/dif. & s/dif. & $-15 \%$ & s/dif. & s/dif. & s/dif. \\
\hline NOx & s/dif. & s/dif. & s/dif. & $-6 \%$ & s/dif. & s/dif. & s/dif. & s/dif. \\
\hline Aldeídos & s/dif. & s/dif. & $57 \%$ & s/dif. & s/dif. & s/dif. & s/dif. & s/dif. \\
\hline $\mathrm{CO}_{2}$ & s/dif. & s/dif. & s/dif. & s/dif. & $-2 \%$ & s/dif. & s/dif. & $-2 \%$ \\
\hline Autonomia Urbana & $-4 \%$ & s/dif. & s/dif. & s/dif. & $-2 \%$ & $-3 \%$ & $-2 \%$ & $-2 \%$ \\
\hline $\begin{array}{c}\text { Autonomia em } \\
\text { Estrada }\end{array}$ & $-2 \%$ & s/dif. & s/dif. & $-2 \%$ & $-3 \%$ & $-3 \%$ & $-3 \%$ & s/dif. \\
\hline
\end{tabular}

Na comparação dos resultados obtidos com E27,5 e E22 (tabela IV), observou-se que, de modo geral, o maior teor de etanol levou a mudanças semelhantes às observadas na comparação entre E25 e E22 (tabela III). A emissão de CO continuou apresentando reduções, porém mais acentuadas (até 21\%), afetando também veículos mais novos. Com relação à emissão de $\mathrm{CO}_{2}$, verificou-se uma redução em dois veículos (1\%). Não foram encontradas mudanças significativas para NMHC e NOx, enquanto para aldeídos foi detectado um aumento pontual (39\% em 1 veículo). Com respeito à autonomia, a redução foi estatisticamente significativa em 5 dos 8 veículos testados, com variações em torno de $2 \%$.

Conforme pode ser observado na tabela $\mathrm{V}$, além da redução no $\mathrm{CO}$ (até $31 \%$ em 3 veículos) e $\mathrm{CO}_{2}$ ( $2 \%$ em 2 veículos), a adição de $30 \%$ de etanol à gasolina trouxe como benefício uma diminuição na emissão de hidrocarbonetos (até $27 \%$ em 2 veículos) e NOx (6\% em 1 veículo). No entanto, houve um aumento mais acentuado na emissão de aldeídos (57\% em 1 veículo). A diminuição detectada na autonomia foi superior à observada com o uso de E27,5 (até 4\% em 6 veículos).

As tabelas VI e VII apresentam a comparação dos resultados obtidos nos modelos com E27,5 e E30 com os de E25.

Tabela VI- Comparação entre emissões e autonomia com E27,5 e E25.

\begin{tabular}{c|l|l|l|l|l|l|l|l}
\hline \multicolumn{7}{c}{ E27,5 x E25 } \\
\hline $\begin{array}{c}\text { Veículo } \\
\text { NHC (L2, L3) \& }\end{array}$ & L2A & L2B & L3A & L3B & L4A & L5A & L5B & L6A \\
\hline SO (L4, L5, L6) & s/dif. & s/dif. & s/dif. & s/dif. & s/dif. & s/dif. & s/dif. & s/dif. \\
\hline NOx & $-11 \%$ & $-8 \%$ & s/dif. & s/dif. & s/dif. & s/dif. & s/dif. & s/dif. \\
\hline Aldeídos & s/dif. & s/dif. & s/dif. & s/dif. & s/dif. & s/dif. & s/dif. & s/dif. \\
\hline $\mathrm{CO}_{2}$ & s/dif. & s/dif. & s/dif. & s/dif. & s/dif. & s/dif. & s/dif. & s/dif. \\
\hline Autonomia Urbana & s/dif. & s/dif. & s/dif. & s/dif. & s/dif. & s/dif. & s/dif. & s/dif. \\
\hline $\begin{array}{c}\text { Autonomia em } \\
\text { Estrada }\end{array}$ & s/dif. & s/dif. & s/dif. & $-1 \%$ & $-1 \%$ & s/dif. & s/dif. & s/dif. \\
\hline
\end{tabular}


Tabela VII- Comparação entre emissões e autonomia com E30 e E25.

\begin{tabular}{c|l|l|l|l|l|l|l|l}
\hline \multicolumn{7}{c}{ E30 x E25 } \\
\hline $\begin{array}{c}\text { Veículo } \\
\text { NHC (L2, L3) \& }\end{array}$ & L2A & L2B & L3A & L3B & L4A & L5A & L5B & L6A \\
\hline sMHC (L4, L5, L6) & s/dif. & s/dif. & s/dif. & s/dif. & s/dif. & s/dif. & s/dif. & s/dif. \\
\hline NO & $-22 \%$ & $-16 \%$ & s/dif. & s/dif. & $-10 \%$ & s/dif. & s/dif. & s/dif. \\
\hline Aldeídos & s/dif. & s/dif. & s/dif. & s/dif. & s/dif. & s/dif. & s/dif. & s/dif. \\
\hline $\mathrm{CO}_{2}$ & s/dif. & s/dif. & s/dif. & s/dif. & s/dif. & s/dif. & s/dif. & s/dif. \\
\hline Autonomia Urbana & $-2 \%$ & s/dif. & s/dif. & s/dif. & $-1 \%$ & s/dif. & s/dif. & $-1 \%$ \\
\hline $\begin{array}{c}\text { Autonomia em } \\
\text { Estrada }\end{array}$ & $-1 \%$ & s/dif. & s/dif. & s/dif. & $-2 \%$ & s/dif. & s/dif. \\
\hline
\end{tabular}

A tabela VI indica um resultado bastante semelhante ao que foi observado na comparação E25 x E22 (tabela III) com mudanças estatisticamente significativas apenas para CO (redução de até $11 \%$ em 2 veículos) e autonomia (redução de $1 \%$ em outros 2 veículos).

Na tabela VII observa-se que, além de uma acentuação das tendências de redução de $\mathrm{CO}$ (até $22 \%$ em 3 veículos) e autonomia (até 2\% em 5 veículos), o aumento do teor de etanol até $30 \%$ também levou à redução do $\mathrm{CO}_{2}$ (1\% em 2 veículos).

\subsection{MOTOCICLETAS}

De acordo com a Resolução CONAMA no 297/2002 [9], os ensaios de emissões e autonomia em ciclomotores, motociclos e similares devem seguir as orientações da Diretiva Europeia $n^{\circ}$ 97/24/EC [10], em que o veículo em teste é submetido à condição de carga controlada em dinamômetro de chassis. Os gases medidos nesse ensaio são os hidrocarbonetos totais (THC), monóxido de carbono (CO), dióxido de carbono $\left(\mathrm{CO}_{2}\right)$ e óxidos de nitrogênio (NOx). As técnicas analíticas para a determinação desses gases são as mesmas adotadas nos testes de veículos leves.

Para o tratamento dos dados e análise dos resultados obtidos com as motocicletas testadas, foi utilizada a mesma metodologia empregada para os veículos, conforme descrito anteriormente, incluindo a realização de pelo menos 3 ensaios.

Numa análise qualitativa, percebeu-se tendências de redução das emissões de THC e $\mathrm{CO}$ (exceção ao THC na moto M2A) conforme aumentou-se o teor de etanol. Na emissão de NOx, observou-se uma tendência de aumento em três das motos testadas (PM1A, M2A e M3A) e neutra nas demais. Para as emissões de $\mathrm{CO}_{2}$ não houve uma tendência definida (aumento na PM1A e M1A e redução na M3B), assim como para autonomia (redução na M1A, M2A e M3A e aumento na PM1A e M3B) [8].

Com relação a este último atributo, destaca-se um comportamento diferente dos automóveis, onde a tendência quase sempre foi de redução. Tal situação pode ser explicada pelo fato das motocicletas até a fase M3 do PROMOT geralmente operarem com relação ar-combustível (RAC) bastante rica. Dessa forma, a utilização de um combustível com maior teor de oxigênio tende a aproximar a RAC da relação 
estequiométrica, resultando em melhora da autonomia. No entanto, para as motocicletas que não operam tão ricas, esse efeito pode ser menos importante, sendo então sobrepujado pelo do menor poder calorífico de misturas que utilizam maior teor de etanol.

As tabelas VIII a X apresentam a comparação entre os combustíveis E25, E27,5 e E30 contra a referência E22 com a mesma metodologia usada anteriormente para os veículos.

Na comparação entre os resultados obtidos com E25 e E22 (tabela VIII), percebem-se reduções das emissões de THC e $\mathrm{CO}$ que chegam respectivamente a $8 \%$ e $18 \%$. No entanto houve um aumento na emissão de $\mathrm{CO}_{2}$, de $4 \%$ em uma moto (PM1A), redução da autonomia da ordem de $1 \%$ na M3B e aumento de $18 \%$ nas emissões de NOx em duas motos (PM1A e M2A).

Tabela VIII- Comparação entre emissões e autonomia com E25 e E22.

\begin{tabular}{c|c|c|c|c|c}
\hline \multicolumn{6}{c}{ E25 x E22 } \\
\hline Motos & PM1A & M1A & M2A & M3A & M3B \\
\hline THC & $-8 \%$ & s/dif. & s/dif. & s/dif. & s/dif. \\
\hline $\mathrm{CO}$ & $-12 \%$ & $-8 \%$ & $-18 \%$ & s/dif. & $-8 \%$ \\
\hline $\mathrm{NOx}$ & $18 \%$ & s/dif. & $18 \%$ & s/dif. & s/dif. \\
\hline $\mathrm{CO}_{2}$ & $4 \%$ & s/dif. & s/dif. & s/dif. & s/dif. \\
\hline Autonomia & s/dif. & s/dif. & s/dif. & $-1 \%$ & s/dif. \\
\hline
\end{tabular}

Com a utilização dos combustíveis E27,5 e E30 percebe-se uma acentuação dos comportamentos acima descritos (exceto para autonomia), conforme pode ser observado nas tabelas IX e X.

Tabela IX- Comparação entre emissões e autonomia com E27,5 e E22

\begin{tabular}{c|c|c|c|c|c}
\multicolumn{6}{c}{ E27,5 x E22 } \\
\hline Motos & PM1A & M1A & M2A & M3A & M3B \\
\hline THC & $-14 \%$ & s/dif. & s/dif. & s/dif. & $-15 \%$ \\
\hline $\mathrm{CO}$ & $-22 \%$ & $-15 \%$ & $-33 \%$ & $-10 \%$ & $-15 \%$ \\
\hline $\mathrm{NOx}$ & $33 \%$ & s/dif. & $32 \%$ & s/dif. & s/dif. \\
\hline $\mathrm{CO}_{2}$ & $7 \%$ & $6 \%$ & s/dif. & s/dif. & s/dif. \\
\hline Autonomia & $3 \%$ & s/dif. & s/dif. & $-1 \%$ & s/dif. \\
\hline
\end{tabular}

Tabela X- Comparação entre emissões e autonomia com E30 e E22

\begin{tabular}{c|c|c|c|c|c}
\hline \multicolumn{6}{c}{ E30 x E22 } \\
\hline Motos & PM1A & M1A & M2A & M3A & M3B \\
\hline THC & $-20 \%$ & $-8 \%$ & s/dif. & s/dif. & $-22 \%$ \\
\hline $\mathrm{CO}$ & $-32 \%$ & $-22 \%$ & $-48 \%$ & $-15 \%$ & $-22 \%$ \\
\hline $\mathrm{NOx}$ & $48 \%$ & s/dif. & $47 \%$ & s/dif. & s/dif. \\
\hline $\mathrm{CO}_{2}$ & $11 \%$ & $9 \%$ & s/dif. & s/dif. & s/dif. \\
\hline Autonomia & $4 \%$ & s/dif. & $5 \%$ & $-2 \%$ & s/dif. \\
\hline
\end{tabular}


Em relação à referência E22, a utilização de E27,5 resultou em reduções mais marcantes nas emissões de THC e CO (até $15 \%$ e 33\%, respectivamente), e aumento das emissões de NOx (até 33\% em duas motos) e de $\mathrm{CO}_{2}$ (até 7\% em duas motos). Quanto à autonomia, a tendência foi indefinida (1\% de redução em uma moto e $3 \%$ de aumento em outra).

Com o uso do E30 as reduções das emissões de THC e CO foram de até $22 \%$ e $48 \%$, respectivamente, porém houve aumento das emissões de NOx em até $48 \%$ em duas motos (PM1A e M2A). As diferenças em $\mathrm{CO}_{2}$ e autonomia se acentuaram mais, com aumento de até $11 \%$ no primeiro caso e tendência indefinida no segundo (aumento de até $5 \%$ em duas motos e redução de $2 \%$ em uma).

$\mathrm{Na}$ comparação dos teores propostos (E27,5 e E30) com E25, percebe-se que para ambos persiste a tendência de redução das emissões de THC e $\mathrm{CO}$ e aumento das emissões de NOx e $\mathrm{CO}_{2}$, conforme indicado nas tabelas XI e XII. A tendência da autonomia segue indefinida, com algumas motos melhorando e outras piorando com esse combustível.

Tabela XI- Comparação entre emissões e autonomia com E27,5 e E25

\begin{tabular}{c|c|c|c|c|c}
\hline \multicolumn{6}{c}{ E27,5 x E25 } \\
\hline Motos & PM1A & M1A & M2A & M3A & M3B \\
\hline THC & $-7 \%$ & s/dif. & s/dif. & s/dif. & s/dif. \\
\hline $\mathrm{CO}$ & $-12 \%$ & $-7 \%$ & $-18 \%$ & s/dif. & $-7 \%$ \\
\hline $\mathrm{NOx}$ & $13 \%$ & s/dif. & $13 \%$ & s/dif. & s/dif. \\
\hline $\mathrm{CO}_{2}$ & $3 \%$ & s/dif. & s/dif. & s/dif. & s/dif. \\
\hline Autonomia & s/dif. & s/dif. & s/dif. & $-1 \%$ & s/dif. \\
\hline
\end{tabular}

Tabela XII- Comparação entre emissões e autonomia com E30 e E25

\begin{tabular}{c|c|c|c|c|c}
\hline \multicolumn{6}{c}{ E30 x E25 } \\
\hline Motos & PM1A & M1A & M2A & M3A & M3B \\
\hline THC & $-14 \%$ & s/dif. & s/dif. & s/dif. & $-15 \%$ \\
\hline $\mathrm{CO}$ & $-23 \%$ & $-15 \%$ & $-36 \%$ & $-10 \%$ & $-15 \%$ \\
\hline $\mathrm{NOx}$ & $25 \%$ & s/dif. & $25 \%$ & s/dif. & s/dif. \\
\hline $\mathrm{CO}_{2}$ & $6 \%$ & $5 \%$ & s/dif. & s/dif. & s/dif. \\
\hline Autonomia & $2 \%$ & s/dif. & s/dif. & $-1 \%$ & s/dif. \\
\hline
\end{tabular}

\section{ENSAIOS DE DESEMPENHO EM PISTA}

\subsection{PARTIDA E DIRIGIBILIDADE A FRIO EM VEÍCULOS}

Os ensaios foram conduzidos em contêineres refrigerados e cada ensaio foi iniciado quando a temperatura do óleo do motor atingiu $0^{\circ} \mathrm{C}$, com tolerância de $3^{\circ} \mathrm{C}$ acima desta temperatura. Antes de cada ensaio com um novo combustível os veículos foram condicionados com rodagem de $10 \mathrm{~km}$ para garantir o reconhecimento do novo combustível, quando aplicável e a remoção do combustível anterior das linhas de alimentação do sistema. 
Cada ensaio consistiu nas seguintes etapas, realizadas após a partida dos veículos:

- Número de tentativas para partida, limitadas a 5 de no máximo 10s cada;

- Observações de falhas na rotação do motor durante a partida;

- Monitoramento da marcha lenta por 30 segundos após a partida;

- Aceleração livre com alcance de $100 \%$ de curso do pedal;

- Dirigibilidade a frio partindo do repouso, com $100 \%$ de aceleração e trocas de marcha em 6000 rpm até a terceira marcha.

Após os ensaios, foi realizada análise gráfica do perfil de rotação do motor em cada caso e feita a correlação destes com os comentários do condutor.

O sistema de aquisição de dados armazena as informações de rotação e temperatura de óleo do motor. O tacômetro é responsável pela coleta e filtragem da rotação do motor via garra indutiva (sinal da vela de ignição) ou sinal de comando de disparo da bobina. O equipamento faz a conversão do sinal de rotação em uma saída de tensão.

Utilizando o software Labview, foi desenvolvido um programa que faz a aquisição de dois canais de dados a $10 \mathrm{~Hz}$ de taxa de aquisição. Um dos canais é o de temperatura do óleo, medido com um termopar do tipo $\mathrm{J}$ e o outro é o de tensão proporcional à rotação do motor. Este software se comunica com hardware composto pela base com comunicação TCP-IP, um cartão de entrada de dados analógicos de temperatura (NI 9211) e um cartão para entrada analógica de tensão (NI 9219). O software armazena os dados em um arquivo texto com colunas contendo a hora, a rotação e a temperatura.

A figura 1 ilustra um resultado típico do perfil de rotação do motor durante o ensaio de partida e dirigibilidade a frio. Nela encontram-se destacadas as etapas de partida, marcha lenta e aceleração livre. Os registros de rotação do motor durante a etapa de dirigibilidade a frio apresentaram ruído elevado no sinal, não sendo apropriado a sua utilização para avaliação dos resultados. Para avaliação desta etapa foram considerados os comentários do condutor do veículo.

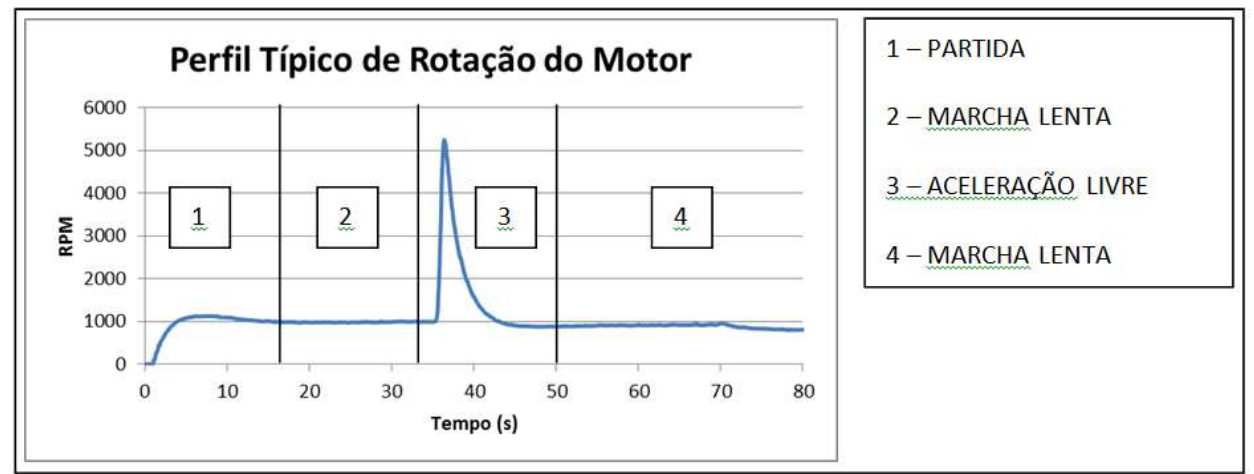

Fig. 1 - Perfil típico de rotação do motor durante as etapas de partida, marcha lenta e aceleração livre.

As figuras 2 a 7 apresentam o perfil de rotação do motor para seis veículos de teste durante a partida, marcha lenta e aceleração livre. Nos veículos L5A e L6B não foi possível realizar o registro da rotação do motor, devido a características dos motores incompatíveis com o sistema de aquisição de dados. Para avaliação do 
comportamento destes veículos foram considerados os comentários do condutor para todas as etapas do ensaio.

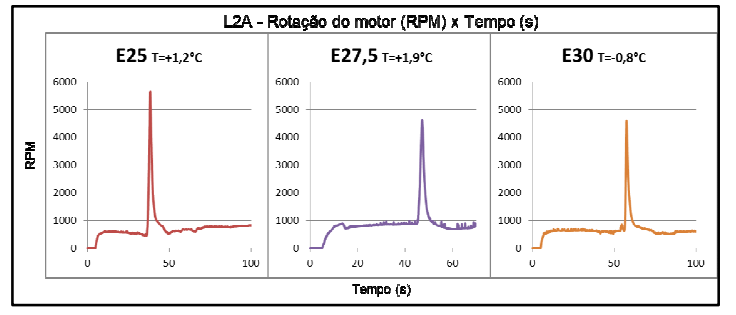

Fig. 2 - Veículo L2A.

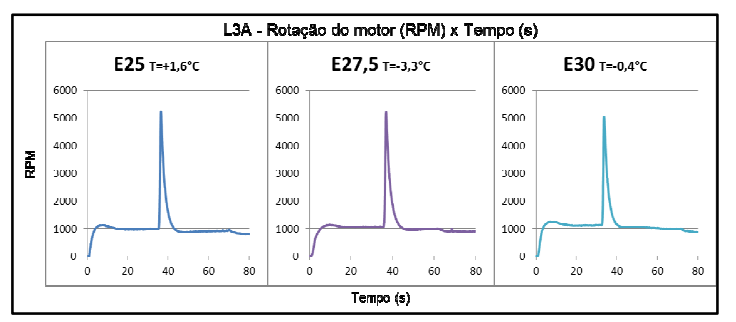

Fig. 4 - Veículo L3A.

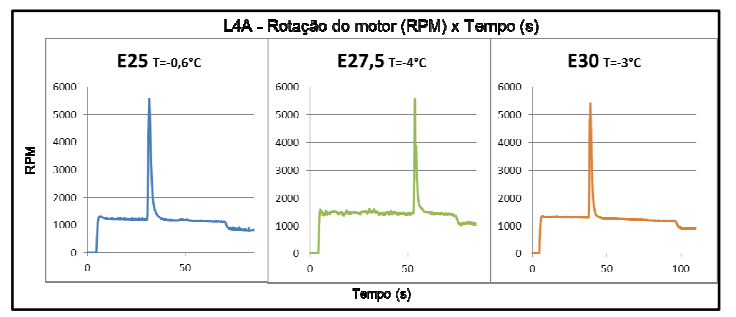

Fig. 6 - Veículo L4A.

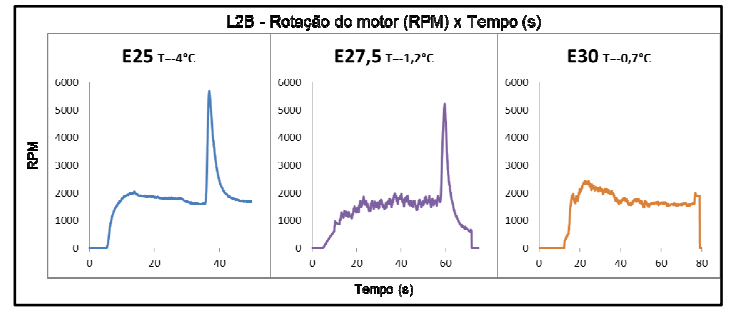

Fig. 3 - Veículo L2B.

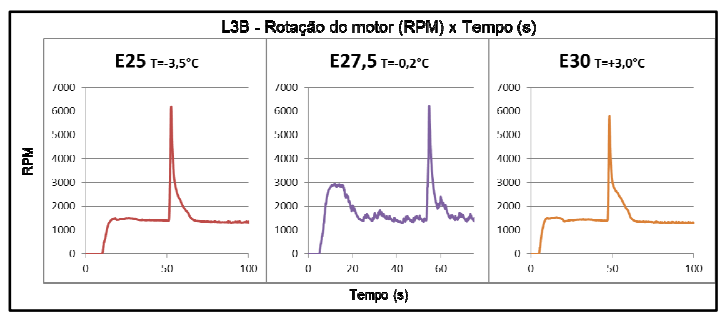

Fig. 5 - Veículo L3B.

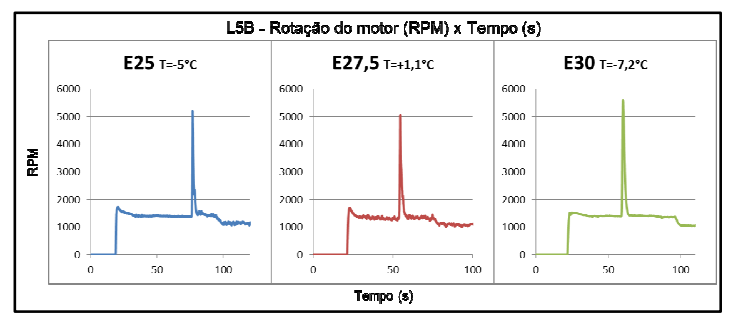

Fig. 7 - Veículo L5B.

Os perfis de rotação mostram que foi possível realizar as etapas de partida, marcha lenta e aceleração livre com os três combustíveis de teste em todos os veículos, com exceção do veículo L2B utilizando E30, que não conseguiu realizar a etapa de aceleração livre.

As variações de rotação dos motores observadas nos períodos de marcha lenta dos veículos L2A, L2B, L3B, L4A e L5B, com E27,5, representam ruído de medição, pois não foram observadas pelo condutor ocorrências com comportamento compatível durante estes ensaios. Sendo assim, tais variações não foram consideradas como falhas de funcionamento.

De acordo com os comentários do condutor do ensaio, apenas os veículos da fase PROCONVE L2 (L2A e L2B), com tecnologia mais antiga, apresentaram falhas leves e médias em algumas etapas do ensaio de partida e dirigibilidade a frio com os três combustíveis de teste. Somente o veículo L2B utilizando E30 apresentou falha severa, não sendo capaz de completar a etapa de aceleração livre. Foi realizada repetição deste ensaio e a etapa de aceleração livre foi cumprida com a ocorrência de falha de intensidade média. É importante ressaltar que mesmo utilizando o combustível E25, os veículos acima mencionados apresentaram falhas em baixa temperatura. 
Com relação aos veículos fabricados a partir da fase PROCONVE L3 não foram observadas falhas em nenhuma das etapas do ensaio de partida e dirigibilidade a frio, sendo todas as etapas cumpridas normalmente. Apenas o veículo L3A apresentou marcha lenta irregular após a etapa de aceleração livre. Porém, essa ocorrência se repetiu para os três combustíveis de teste, sendo, por isso, descartada como falha devido ao combustível.

\subsection{RETOMADAS DE VELOCIDADE EM VEÍCULOS}

As avaliações de desempenho dos veículos, com diferentes combustíveis foram realizadas a partir de ensaios de retomadas de velocidade em pista de testes. A metodologia foi baseada na prática recomendada SAE J1491:2006 [11] e consiste na medição do tempo decorrido durante as retomadas de velocidade entre 40 e $80 \mathrm{~km} / \mathrm{h}$, 60 e $100 \mathrm{~km} / \mathrm{h}$ e 80 e $120 \mathrm{~km} / \mathrm{h}$. Respectivamente a cada um desses intervalos de velocidades, os veículos de câmbio manual são testados com a antepenúltima, penúltima e última marcha acopladas. Os veículos de câmbio automático são ensaiados na posição "D” (drive).

Neste procedimento, a velocidade do veículo é inicialmente estabilizada no valor mínimo do intervalo, com a marcha correspondente acoplada. É então realizada aceleração plena até que o valor máximo de velocidade do intervalo seja alcançado e o tempo decorrido neste período é registrado.

Para as medições dos tempos de retomada de velocidades foi utilizado o sensor ótico Correvit L350 Acqua que instalado na lateral do veículo registra as distâncias, velocidades e tempos de deslocamento. O resultado de cada ensaio é composto pela média entre os tempos obtidos em retomadas consecutivas nas direções opostas da pista, com o objetivo de anular possíveis diferenças de inclinação de piso e direção do vento. São aceitos todos os resultados com variação inferior a $10 \%$ entre as medições nas duas direções.

Para cada combustível ensaiado, foram realizados pelo menos 12 ensaios, em cada intervalo de velocidades, e considerados válidos todos os resultados cujas variações em relação à média foram inferiores a 3\%. A dispersão de cada conjunto de resultados válidos é medida pelo coeficiente de variação, que também é limitado em $3 \%$ para a aprovação final dos ensaios.

No tratamento estatístico, quando se verificou a influência do combustível como significativa a partir do teste $t$ de Student, a um nível de confiança superior a 95\% ( $p$ level < 0,05), as médias foram comparadas entre si pelo cálculo da diferença percentual [12]. Nos casos em que a hipótese de igualdade estatística entre as médias não pôde ser descartada, os resultados foram apresentados como "s/dif.".

Nas tabelas XIII e XIV são apresentadas as diferenças percentuais em relação ao combustível de referência E25, respectivamente para o E27,5 e E30.

Nestas tabelas, as variações negativas representam uma redução nos tempos de retomada de velocidade e, portanto, melhores desempenhos (destacados em verde). Variações positivas indicam desempenho pior (em vermelho). Quando não foram 
identificadas diferenças estatisticamente significativas, foi incluída a indicação "s/dif".

Tabela XIII - Diferenças percentuais das retomadas de velocidade com E27,5 e E25

Retomadas de Velocidade - E27,5 x E25

Diferenças Percentuais (\%)

\begin{tabular}{c|c|c|c}
\hline Veículos & $40-80 \mathrm{~km} / \mathrm{h}$ & $60-100 \mathrm{~km} / \mathrm{h}$ & $80-120 \mathrm{~km} / \mathrm{h}$ \\
\hline L2B & $2,6 \%$ & $\mathrm{~s} / \mathrm{dif}$ & $\mathrm{s} / \mathrm{dif}$ \\
\hline L3A & s/dif & $\mathrm{s} / \mathrm{dif}$ & $\mathrm{s} / \mathrm{dif}$ \\
\hline L3B & $\mathrm{s} /$ dif & $\mathrm{s} / \mathrm{dif}$ & $\mathrm{s} / \mathrm{dif}$ \\
\hline L4A & $-1,7 \%$ & $\mathrm{~s} / \mathrm{dif}$ & $\mathrm{s} / \mathrm{dif}$ \\
\hline L5A & $\mathrm{s} /$ dif & $\mathrm{s} / \mathrm{dif}$ & $\mathrm{s} / \mathrm{dif}$ \\
\hline L5B & $\mathrm{s} /$ dif & $1,5 \%$ & $\mathrm{~s} / \mathrm{dif}$ \\
\hline L6B & s/dif & $-1,9 \%$ & $-1,4 \%$ \\
\hline
\end{tabular}

Verifica-se que, de uma forma geral, os veículos ensaiados foram pouco sensíveis às variações do teor de etanol na gasolina de $25 \%$ para $27,5 \%$, não havendo diferenças importantes na maioria dos ensaios. Dois dos sete veículos ensaiados (L2B e L5B) apresentaram tendências marginais de piora do desempenho e outros dois de melhora (L4A e L6B).

Tabela XIV - Diferenças percentuais das retomadas de velocidade com E30 e E25

\section{Retomadas de Velocidade - E30 x E25 Diferenças Percentuais (\%)}

\begin{tabular}{c|c|c|c}
\hline Veículos & $40-80 \mathrm{~km} / \mathrm{h}$ & $60-100 \mathrm{~km} / \mathrm{h}$ & $80-120 \mathrm{~km} / \mathrm{h}$ \\
\hline L2B & s/dif & $1,5 \%$ & s/dif \\
\hline L3A & $1,7 \%$ & s/dif & s/dif \\
\hline L3B & $1,4 \%$ & s/dif & s/dif \\
\hline L4A & $-3,4 \%$ & s/dif & s/dif \\
\hline L5A & $-1,9 \%$ & $-1,5 \%$ & $-1,6 \%$ \\
\hline L5B & $3,6 \%$ & s/dif & $3,4 \%$ \\
\hline L6B & $-2,6 \%$ & $-3,3 \%$ & $-2,3 \%$ \\
\hline
\end{tabular}

Em relação ao uso do E30, pode-se observar que houve mais casos de diferenças estatisticamente significativas, com variações de até 3,6\%. Neste caso, observa-se que, da amostra ensaiada, quatro dos sete veículos apresentaram tendências de piora no desempenho, sendo mais consistentes nos veículos de tecnologias mais antigas (L2B, L3A e L3B). Nos veículos com tecnologias mais atuais a tendência observada foi de pequena melhora no desempenho, à exceção do veículo L5B.

\section{CURVAS CARACTERÍSTICAS EM BANCO DE PROVAS DE MOTOR}

Foram levantadas as curvas características de um motor comercial de ignição por centelha, 
quatro cilindros em linha, injeção direta de gasolina com turbo compressor e intercooler que equipa alguns modelos de veículos do mercado nacional. $\mathrm{O}$ motor foi instalado em banco de provas e operou em condições controladas de temperatura de admissão $\left(25^{\circ} \mathrm{C} \pm 2{ }^{\circ} \mathrm{C}\right)$, umidade do ar de admissão antes do compressor (50\%), temperatura da água de arrefecimento $\left(92^{\circ} \mathrm{C} \pm 2^{\circ} \mathrm{C}\right)$, temperatura do óleo lubrificante $\left(100^{\circ} \mathrm{C}\right.$, máximo) e temperatura do combustível $\left(20^{\circ} \mathrm{C}\right)$. Foi instalada uma sonda lambda de banda larga no escapamento, antes do catalisador do motor, para monitoramento das condições da mistura ar-combustível durante os ensaios.

As curvas de potência efetiva, consumo específico de combustível e temperatura de escapamento antes do catalisador foram obtidas em plena carga e com 50\% de carga, em cada rotação. Os valores de torque correspondentes às curvas com $50 \%$ de carga foram levantados previamente com o combustível de referência (E25) e mantidos constantes nos ensaios com os três combustíveis (E25, E27,5 e E30). Os ensaios foram realizados baseados na Norma ABNT NBR ISO 1585 [13].

Para efeito de tratamento estatístico dos dados realizaram-se três curvas de potência em plena carga e três curvas com $50 \%$ de carga para cada produto. As médias dos resultados das variáveis de interesse com os diferentes combustíveis foram comparadas estatisticamente, pela técnica de ANOVA, utilizando um nível de confiança de 95\%. Baseado no histórico dos ensaios do laboratório estima-se uma incerteza de medição máxima de $1 \%$ nos resultados das variáveis de interesse. Em cada condição, o motor foi operado durante um minuto para estabilização, seguido de mais um minuto para gravação das variáveis de interesse. A potência foi corrigida para uma condição de referência $\left(25^{\circ} \mathrm{C}\right.$ e $\left.99 \mathrm{kPa}\right)$ segundo a Norma ABNT NBR ISO 1585.

Os resultados referentes às curvas de potência corrigida são apresentados nas figuras 8 e 9 , comparando-se, respectivamente, o desempenho dos combustíveis E27,5 e E30 em relação à referência E25. De forma geral, os resultados não apresentaram diferenças estatisticamente significativas. As diferenças máximas foram de $-2,3 \%$ e $-1,6 \%$, respectivamente, somente encontradas nas rotações até $2500 \mathrm{rpm}$.

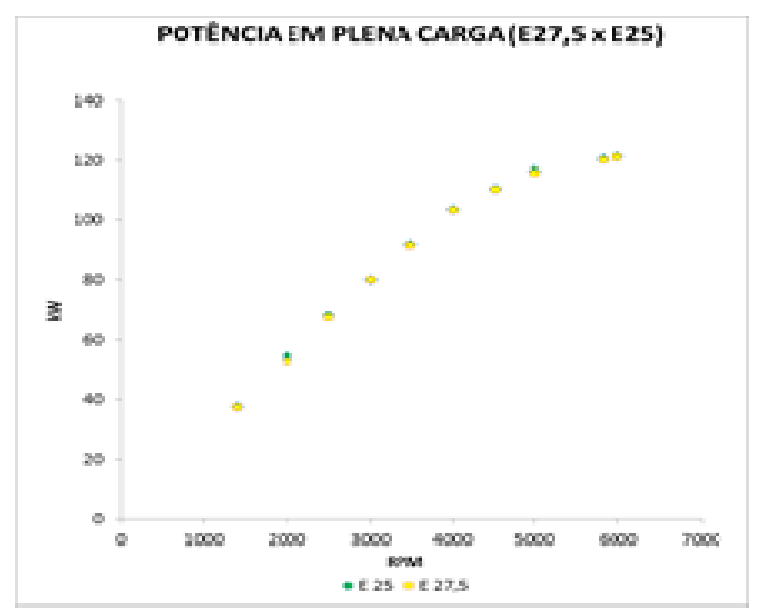

Fig. 8 - E27,5 x E25

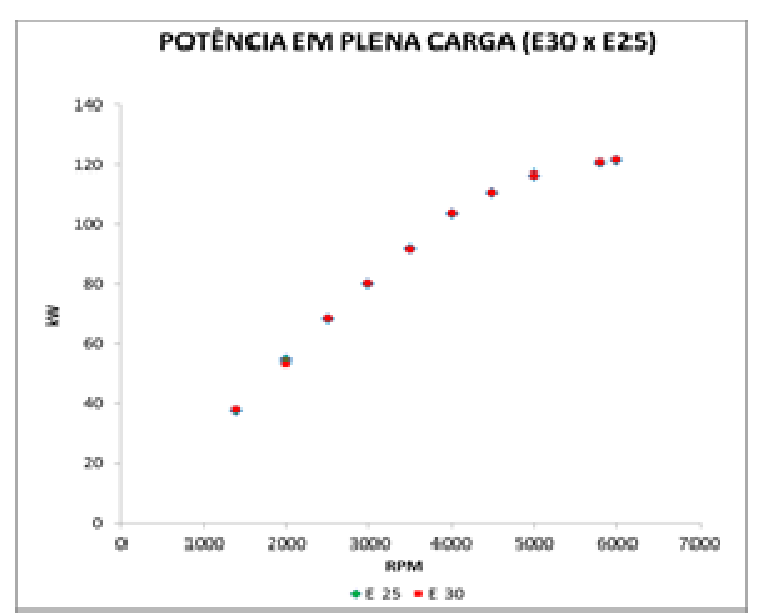

Fig. $9-\mathrm{E} 30$ x E25

Nas figuras 10 a 13 são apresentados os resultados de consumo específico em plena carga e $50 \%$, comparando o E27,5 e o E30 com o E25. Houve aumento de até 2,5\%, principalmente em função da redução do poder calorífico da mistura para maiores teores de etanol. 


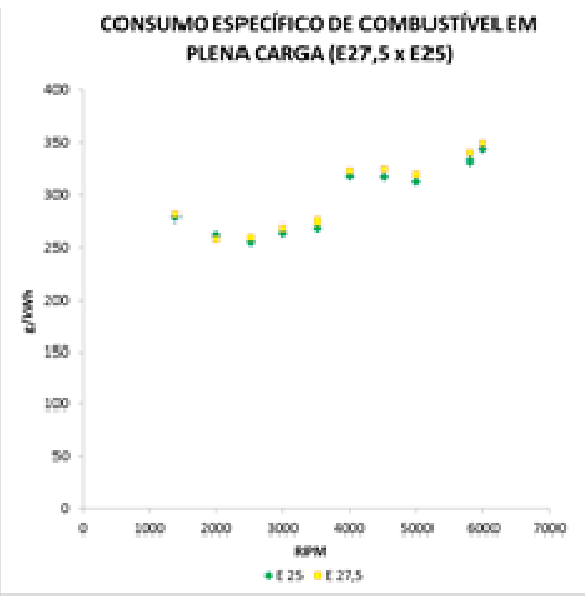

Fig. 10 - Plena carga E27,5 x E25

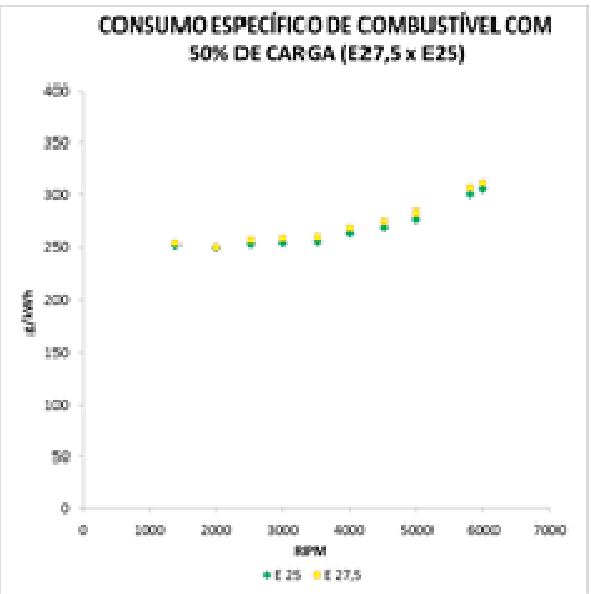

Fig. 12 - Carga parcial E27,5 x E25

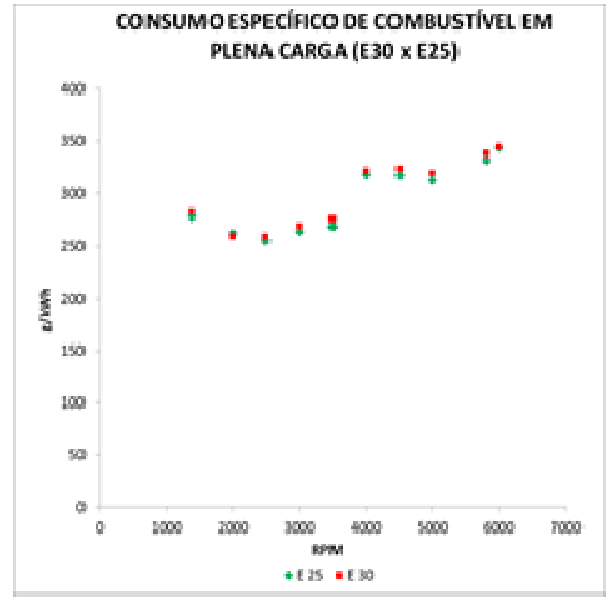

Fig. 11 - Plena carga E30 x E25

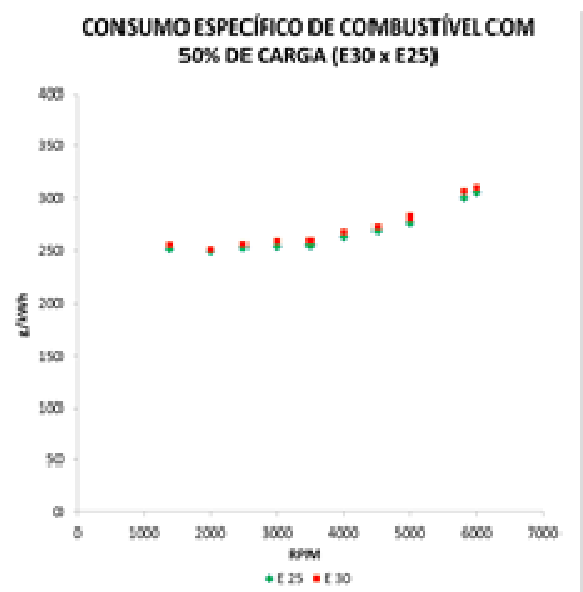

Fig. 13 - Carga parcial E30 x E25.

Com relação à temperatura de escapamento, a condição mais crítica é a de plena carga. Os resultados foram medidos antes do catalisador e estão mostrados nas figuras 14 e 15 .

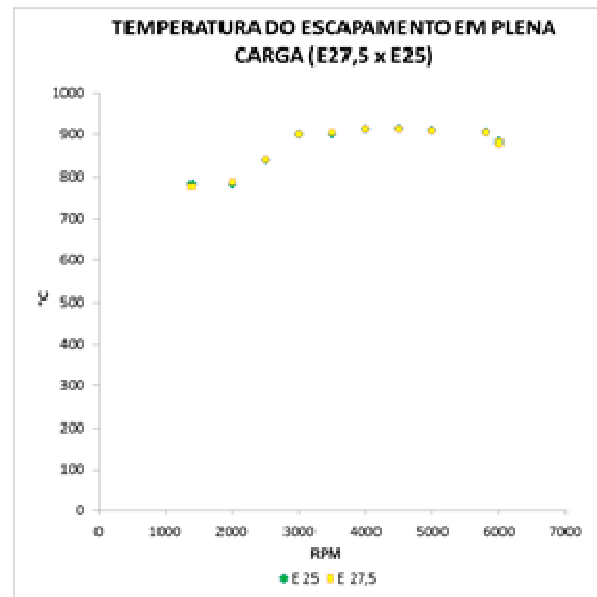

Fig. $25-E 27,5$ x E25

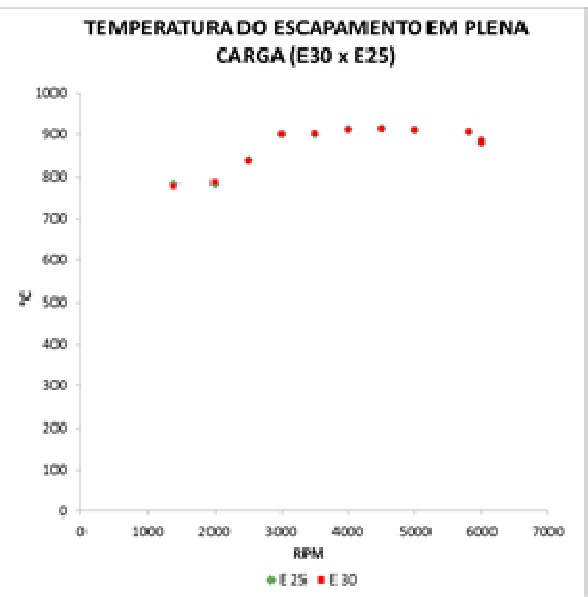

Fig. $26-E 30 \times$ E25

De maneira geral, a temperatura de escapamento em plena carga não apresentou diferenças estatisticamente significativas nas comparações entre o E27,5 e o E30 em relação ao E25. As 
variações máximas encontradas foram da ordem de $1 \%$, dentro da incerteza de medição.

\section{AVALIAÇÃO DE PROPRIEDADES FÍSICO-QUÍMICAS}

A presença de etanol na gasolina causa alterações em suas propriedades físico-químicas, que podem afetar o desempenho dos motores. As principais vantagens associadas ao uso de etanol são: maior resistência à detonação e menor nível de emissões de $\mathrm{CO}_{2}$. Entretanto, algumas possíveis desvantagens como o aumento do consumo, dificuldade de partida a frio, aumento da formação de goma e da volatilidade, também devem ser consideradas. No presente artigo são avaliados alguns desses efeitos nas propriedades físico-químicas de misturas gasolina/etanol, para proporções de 25, 27,5 e 30\% de etanol anidro na mistura.

Para a avaliação das propriedades físico-químicas da gasolina com diferentes teores de etanol anidro foram selecionadas gasolinas de duas diferentes refinarias. A caracterização destes combustíveis segundo a resolução ANP 40/2013 [14] está apresentada na tabela XV.

Tabela XV - Resultados de Caracterização das Gasolinas Analisadas

\begin{tabular}{|c|c|c|c|}
\hline \multirow{2}{*}{ Propriedades } & \multirow{2}{*}{$\begin{array}{l}\text { Métodos } \\
\text { Utilizados }\end{array}$} & \multicolumn{2}{|c|}{ Resultados } \\
\hline & & AMOSTRA A & AMOSTRA B \\
\hline Aspecto & Visual & LII & LII \\
\hline Cor & Visual & amarelo claro & levemente amarelo \\
\hline Corrosividade ao cobre & ASTM D130 & $1 \mathrm{a}$ & $1 \mathrm{a}$ \\
\hline $\begin{array}{l}\text { Destilação: } \\
\text { PIE, C } \\
10 \% \text { evaporado, }{ }^{\circ} \mathrm{C} \\
50 \% \text { evaporado, }{ }^{\circ} \mathrm{C} \\
90 \% \text { evaporado, }{ }^{\circ} \mathrm{C} \\
\text { PFE, }{ }^{\circ} \mathrm{C} \\
\text { Resíduo, \%v }\end{array}$ & $\begin{array}{l}\text { ASTM D86 } \\
\text { (automático) }\end{array}$ & $\begin{array}{c}33,6 \\
54,0 \\
101,9 \\
167,4 \\
206,2 \\
1,0 \\
\end{array}$ & $\begin{array}{c}31,7 \\
53,4 \\
95,1 \\
162,4 \\
204,7 \\
1,0 \\
\end{array}$ \\
\hline Teor de Enxofre, $\mathrm{mg} / \mathrm{kg}$ & ASTM D5453 & 32 & 50 \\
\hline Goma atual lavada, mg/100 mL & ASTM D381 & 1,0 & $<0,5$ \\
\hline Massa específica a $20^{\circ} \mathrm{C}, \mathrm{kg} / \mathrm{m}^{3}$ & ASTM D4052 & 739,6 & 731,3 \\
\hline Pressão de vapor a $37,8^{\circ} \mathrm{C}, \mathrm{kPa}$ & ASTM D5191 & 58,5 & 48,0 \\
\hline $\begin{array}{l}\text { Tipos de Hidrocarbonetos: } \\
\text { Aromáticos, \%vol. } \\
\text { Olefínicos, \%vol. } \\
\text { Saturados, \%vol. } \\
\text { Não identificados, \%vol. }\end{array}$ & CG & $\begin{array}{c}29,2 \\
18,4 \\
52,1 \\
0,3 \\
\end{array}$ & $\begin{array}{c}22,0 \\
25,3 \\
52,2 \\
0,5 \\
\end{array}$ \\
\hline Benzeno, \%vol. & $\mathrm{CG}$ & 1,05 & 0,79 \\
\hline
\end{tabular}

LII - límpido e isento de impurezas

O parâmetro que melhor define a volatilidade de um combustível é a pressão de vapor. Em geral, o teor de etanol na gasolina, em até $20 \%$, aumenta a pressão de vapor, resultando em um aumento da volatilidade da gasolina $\mathrm{C}$, e consequente aumento em perdas evaporativas. Em concentrações maiores de etanol, a pressão de vapor tende a diminuir [15]. Os resultados de pressão de vapor nas misturas avaliadas estão apresentados na tabela XVI. 
Tabela XVII - Avaliação da pressão de vapor de gasolinas com diferentes teores de etanol.

\begin{tabular}{|c|c|c|c|}
\hline \multirow{2}{*}{ Pressão de vapor, KPa } & \multicolumn{3}{|c|}{ Resultados (ASTM D5191) ${ }^{* 1}$} \\
\cline { 2 - 4 } & E25 & E27,5 & E30 \\
\hline Amostra A & 63,4 & 62,9 & 62,5 \\
\hline Amostra B & 53,1 & 52,7 & 52,4 \\
\hline
\end{tabular}

\footnotetext{
${ }^{1}$ A repetibilidade do método ASTM D5191 [16] é igual a 1,3 KPa para uma de pressão de vapor de 60Kpa. A comparação dos valores foi feita pela repetibilidade do método, uma vez que todos os resultados foram obtidos no mesmo dia, pelo mesmo técnico, sob as mesmas condições operacionais.
}

Embora numericamente exista uma tendência de diminuição da pressão de vapor neste intervalo, todos os resultados obtidos para as amostras A e B com 25, 27,5 e 30\% de etanol anidro estão dentro da incerteza do método experimental. Portanto, o aumento do teor de etanol anidro de 25 para $30 \%$ tem pouca influência na pressão de vapor da gasolina C.

O conceito de lubricidade pode ser definido como sendo a capacidade de um fluido de evitar a fricção e o desgaste entre superfícies metálicas em movimento relativo, ao promover uma lubrificação. Quanto maior a lubricidade do fluido, menor será o atrito gerado e, consequentemente, menor o desgaste aferido.

Não existe um método padronizado para avaliação de lubricidade da gasolina. Em geral, utiliza-se o método para óleo Diesel (ASTM D6079) [17] do ensaio HFRR - High Frequency Reciprocating Rig Method adaptado para a gasolina a partir da modificação do recipiente de ensaio para prevenir perdas evaporativas excessivas. Os resultados obtidos nas misturas avaliadas estão apresentados na tabela XVII.

Tabela XVII - Avaliação da lubricidade de gasolinas com diferentes teores de etanol.

\begin{tabular}{|c|c|c|c|}
\hline \multirow{2}{*}{ Lubricidade, $\boldsymbol{\mu m}$} & \multicolumn{3}{|c|}{ Resultados (ASTM D6079) ${ }^{* 2}$} \\
\cline { 2 - 4 } & E25 & E27,5 & E30 \\
\hline Amostra A & 696 & 684 & 670 \\
\hline Amostra B & 706 & 694 & 684 \\
\hline
\end{tabular}

${ }^{* 2}$ A repetibilidade do método ASTM D6079 é igual a $50 \mu \mathrm{m}$ para amostras de óleo diesel; para amostras de gasolina, que utilizam um método modificado, esta incerteza é ainda maior. A comparação dos valores foi feita pela repetibilidade do método, uma vez que todos os resultados foram obtidos no mesmo dia, pelo mesmo técnico, sob as mesmas condições operacionais.

Embora numericamente exista uma tendência de melhoria da lubricidade (diminuição da ranhura) neste intervalo, todos os resultados obtidos para as amostras A e B com 25, 27,5 e $30 \%$ de etanol anidro combustível estão dentro da incerteza do método experimental. Portanto, o aumento do teor de etanol anidro na gasolina de 25 para $30 \%$ tem pouca influência na lubricidade da gasolina $\mathrm{C}$.

A degradação da gasolina com o tempo é um fenômeno natural devido à oxidação. Este fenômeno é acelerado pela presença de oxigênio, luz e aumento da temperatura. A velocidade em que ocorre varia também em função da composição química da gasolina. A oxidação da gasolina é caracterizada principalmente pela formação de goma. Este resíduo pode afetar a dirigibilidade do veículo, reduzir o desempenho do motor e aumentar as emissões de poluentes para o meio ambiente. Em geral, a presença do etanol na gasolina contribui para a 
degradação do produto, acelerando o processo de oxidação. Estudos com misturas gasolina/etanol contendo $25 \%$ de etanol [18] indicaram que a adição de álcool na gasolina reduz a estabilidade da gasolina $\mathrm{C}$, contribuindo para o aumento da formação de goma durante a estocagem.

Para a avaliação da estabilidade à oxidação da gasolina podem ser realizados ensaios ditos acelerados. Dos diferentes testes utilizados, o citado como mais confiável para predizer a estabilidade de gasolina é o teste de envelhecimento a $43^{\circ} \mathrm{C}$, por 4,8 ou mais semanas. Grande parte dos trabalhos publicados na literatura técnica cita que este teste reproduz, com bom grau de confiança e de forma mais rápida, o processo de oxidação à temperatura ambiente $[19,20]$.

Para avaliar a influência do teor de etanol na formação de goma, as amostras avaliadas foram envelhecidas a $43{ }^{\circ} \mathrm{C}$, usando uma adaptação do método ASTM D4625 [21], que minimiza a evaporação do combustível. O teor de goma foi então avaliado ao final de 4 e 8 semanas de estocagem para as amostras A e B. Os resultados do ensaio de envelhecimento nas misturas avaliadas estão apresentados na tabela XVIII. Para estes ensaios, todas as misturas foram feitas em duplicata.

Tabela XVIII - Ensaios de envelhecimento a $43{ }^{\circ} \mathrm{C}$ (ASTM D4625).

\begin{tabular}{|l|c|c|c|c|c|c|}
\hline \multirow{2}{*}{$\begin{array}{c}\text { Goma atual lavada, } \\
\text { mg/100 mL }\end{array}$} & \multicolumn{5}{c|}{ Resultados (ASTM D381) *3 } \\
\cline { 2 - 7 } & \multicolumn{2}{|c|}{ E25 } & \multicolumn{2}{c|}{ E27,5 } & \multicolumn{2}{c|}{ E30 } \\
\hline Amostra A (inicio) & \multicolumn{2}{|c|}{$<0,5$} & \multicolumn{2}{c|}{$<0,5$} & \multicolumn{2}{c|}{$<0,5$} \\
\hline Amostra A, 4 semanas & $<0,5$ & $<0,5$ & 1,0 & 2,0 & $<0,5$ & $<0,5$ \\
\hline Amostra A, 8 semanas & $<0,5$ & $<0,5$ & $<0,5$ & $<0,5$ & $<0,5$ & $<0,5$ \\
\hline Amostra B (início) & \multicolumn{2}{|c|}{1,5} & \multicolumn{2}{c|}{0,5} & \multicolumn{2}{c|}{1,5} \\
\hline Amostra B, 4 semanas & 2,5 & 2,0 & 2,0 & 2,0 & $<0,5$ & $<0,5$ \\
\hline Amostra B, 8 semanas & 2,5 & 3,0 & 3,0 & 2,0 & 2,5 & 2,5 \\
\hline
\end{tabular}

${ }^{3}$ A reprodutibilidade do método ASTM D381 [22] é igual a 2,0 mg/100 mL para valores de goma atual de 0,5 mg/ $100 \mathrm{~mL}$. Como neste caso os ensaios não foram realizados no mesmo dia, foi usada a reprodutibilidade para comparar os resultados.

Apesar da variabilidade numérica dos valores de goma durante os ensaios de envelhecimento, todos os resultados para o mesmo tempo de estocagem de cada amostra com 25, 27,5 e 30\% de etanol estão dentro da incerteza do método experimental. Portanto, o aumento do teor de etanol anidro na gasolina de $25 \%$ para $30 \%$ tem pouca influência na estabilidade à oxidação.

\section{CONCLUSÕES}

No tocante às emissões, com o aumento do teor de etanol entre os níveis de 22 e $30 \% \mathrm{v} / \mathrm{v}$, considerando a amostra de 8 veículos testados, observou-se como tendência geral a manutenção ou redução nas emissões de hidrocarbonetos (THC e $\mathrm{NMHC}$ ), $\mathrm{CO}$ e $\mathrm{CO}_{2}$. A emissão de NOx dos veículos mais antigos (L2 e L3) também seguiu essa tendência, porém para os mais novos (veículos L4 em diante) ocorreu aumento em um dos veículos, enquanto para os demais não houve diferença estatisticamente significativa. Para aldeídos, observou-se um aumento da emissão em 3 veículos. Com relação à autonomia (urbana e em estrada), identificou-se tendência de redução em todos os veículos. Na comparação entre o E27,5 e o 
E25, verificou-se mudanças estatisticamente significativas apenas para $\mathrm{CO}$ (redução de até $11 \%$ em 2 veículos) e autonomia (redução de $1 \%$ em outros 2 veículos).

Quanto aos ensaios de dirigibilidade e partida a frio, os veículos de teste com tecnologia mais antiga (PROCONVE L2) apresentaram falhas com os três combustíveis de teste. Com relação aos veículos fabricados a partir da fase PROCONVE L3 não foram observadas falhas em quaisquer das etapas dos ensaios de partida e dirigibilidade a frio, sendo todas estas concluídas normalmente. Em relação aos ensaios de retomada de velocidade, com base na amostra ensaiada, verifica-se que o aumento do teor de etanol de $25 \%$ para $27,5 \%$ na gasolina $\mathrm{C}$ ocasionou variações da ordem de $2 \%$, para mais ou para menos.

Da mesma forma que os automóveis, para as cinco motocicletas testadas, houve tendência de redução nas emissões de THC e CO com o aumento do teor de etanol. Para as emissões de $\mathrm{CO}_{2}$ e autonomia não houve tendências definidas. Na emissão de NOx, foi observada tendência de manutenção ou aumento. Na comparação entre os resultados obtidos com E27,5 e E25, verificou-se reduções de até 7\% em THC, $18 \%$ em CO e 1\% na autonomia, além de uma elevação em NOx (13\%) e $\mathrm{CO}_{2}(3 \%)$. Em relação aos ensaios de dirigibilidade e partida a frio e retomada de velocidade, realizados pela ABRACICLO, a mesma considerou viável a utilização do E27,5.

De forma geral, os resultados de potência efetiva em plena carga não apresentaram diferenças de desempenho estatisticamente significativas para o E27,5 em relação ao E25, exceto nas condições até $2500 \mathrm{rpm}$, com reduções de $0,8 \%$ a 2,3\%. O consumo específico, nas condições de plena carga e carga parcial, apresentou aumento de até 2,5\%. Para a temperatura de escapamento, mais crítica em plena carga, essas diferenças oscilaram em até $1 \%$ em torno dos valores obtidos para o E25, dentro da incerteza de medição do experimento.

Quanto às propriedades físico-químicas avaliadas, observou-se que todos os resultados ficaram dentro da incerteza dos métodos utilizados. Portanto, o aumento do teor de etanol anidro na gasolina de 25 para $27,5 \%$ tem pouca influência na pressão de vapor, lubricidade e estabilidade à oxidação da gasolina $\mathrm{C}$.

No cômputo geral, não foi identificada qualquer contraindicação ao aumento do teor de etanol na gasolina para $27,5 \%$. Com base nos estudos realizados, o governo federal decidiu fixar a partir de 16 de março de 2015 em $27 \%$ o percentual da mistura de etanol anidro à gasolina.

\section{REFERÊNCIAS}

[1] AGÊNCIA NACIONAL DO PETRÓLEO, GÁS NATURAL E BIOCOMBUSTÍVEIS (ANP), Resolução ANP nº75/2015;

[2] AGÊNCIA NACIONAL DO PETRÓLEO, GÁS NATURAL E BIOCOMBUSTÍVEIS (ANP), Resolução ANP n5/2005;

[3] AGÊNCIA NACIONAL DO PETRÓLEO, GÁS NATURAL E BIOCOMBUSTÍVEIS (ANP), Resolução ANP n6/2005;

[4] MINISTÉRIO DE MINAS E ENERGIA, Inventário Nacional de Emissões Atmosféricas por Veículos Automotores Rodoviários - Relatório Final 2013 - Ano Base 2012; 
[5] ASSOCIAÇÃO BRASILEIRA DE NORMAS TÉCNICAS, Determinação de Hidrocarbonetos, Monóxido de Carbono, Óxidos de Nitrogênio e Dióxido de Carbono no Gás de Escapamento - ABNT NBR 6601, setembro de 2012;

[6] ASSOCIAÇÃO BRASILEIRA DE NORMAS TÉCNICAS, Veículos rodoviários automotores leves - Determinação de aldeídos e cetonas contidos no gás de escapamento, por cromatografia líquida - Método DNPH - ABNT NBR 12026, abril de 2009;

[7] ASSOCIAÇÃO BRASILEIRA DE NORMAS TÉCNICAS, Veículos Rodoviários Automotores Leves - Medição do Consumo de Combustível - Método de Ensaio ABNT NBR 7024, novembro de 2006;

[8] MINISTÉRIO DAS MINAS E ENERGIA (MME), RT PETROBRAS/CENPES DPM n 008/14 - "Efeitos do E27,5 e do E30 em Veículos, Motocicletas e Motor à Gasolina", outubro de 2014;

[9] CONSELHO NACIONAL DO MEIO AMBIENTE, Resolução CONAMA no 297/2002;

[10] PARLAMENTO EUROPEU, Diretiva 97/24/CE, 1997;

[11] SOCIETY OF AUTOMOTIVE ENGINEERS, "Vehicle Acceleration Measurement", SAE Recommended Practice J1491, July 2006;

[12] Montgomery D. C.., George C. R.; Estatística Aplicada e Probabilidade para Engenheiros - LTC Editora, 2003;

[13] ASSOCIAÇÃO BRASILEIRA DE NORMAS TÉCNICAS, Veículos rodoviários Código de ensaio de motores - Potência líquida efetiva, ABNT NBR ISO 1585, junho de 1996;

[14] AGÊNCIA NACIONAL DO PETRÓLEO, GÁS NATURAL E BIOCOMBUSTÍVEIS (ANP), Resolução ANP n40/2013;

[15] Orbital Engine Company. A Literature Review Based Assessment on the Impacts of a $10 \%$ and 20\% Ethanol Gasoline Fuel Blend on Non-Automotive Engines, Report to Environment Australia, 2002;

[16] ASTM D5191 Standard Test Method for Vapor Pressure of Petroleum Products (Mini Method). United States: ASTM International, 2013;

[17] ASTM D6079 Standard Test Method for Evaluating Lubricity of Diesel Fuels by the High-Frequency Reciprocating Rig (HFRR). United States: ASTM International, 2011;

[18] Jeuland, N., Montagne, X. e Gautrot, X. Potentiality of Ethanol as a Fuel for Dedicated Engine, Oil \& Gas Science and Technology - Rev. IFP, Vol. 59 (6), pp. 559-570, 2004.

[19] D’Ornellas, Claudia V. e Alchorne, J. A. Adequação da qualidade da gasolina quanto a estabilidade à estocagem. PETROBRAS, CENPES, Divisão de Tecnologia de Produtos, 1997 (Relatório DIPROD 003/97).

[20] Martins, Claudio S. V. e Alchorne, Jorge A. Exportação de etanol e misturas gasolinaetanol - Aspectos relativos à qualidade dos produtos. PETROBRAS, CENPES, Combustíveis, 2006. (Relatório Técnico COMB 005/2006);

[21] ASTM D4625 Standard Test Method for Middle Distillate Fuel Storage Stability at $43^{\circ} \mathrm{C}\left(110^{\circ} \mathrm{F}\right)$, United States: ASTM International, 2014;

[22] ASTM D381 Standard Test Method for Gum Content in Fuels by Jet Evaporation., 2012. 